\title{
Simultaneous thermal analyses under high pressure and high temperature: a precious tool for investigation of hydrogen storage and biomass gasification
}

\author{
H.-W. Marx, and H. Rädel \\ Linseis Messgeräte GmbH, Vielitzer Str. 43, D-95100 Selb, Allemagne
}

In recent years, the need for clean and sustainable energy initiated investigations on different technologies for transformation and storage of energy. Hydrogen technology and biomass gasification are two of those topics.

One of the main tasks in hydrogen technology is the challenge of hydrogen storage. Storage can be done by capture on metal hydrides. This process should be reversible at reasonable temperatures and pressures. Thermal analysis, especially thermogravimetry (TGA) and differential thermal analyses (DTA) are useful methods for the investigation of potential hydrogen storage media. Obviously, the instrument has to resist to gas atmosphere at high temperatures and pressures. An example of hydrogen release/capture of $\mathrm{TiH}_{2}$ will be shown in order to demonstrate the utility of simultaneous thermal analyses under high pressure/high temperature conditions (STA-HP; ATG-DTA) for such type of investigations.

A further approach in energy technology is transformation of biomass to combustible gases (fuels, syngas). Biomass (organic, carbon containing material) is heated with a limited quantity of oxygen and/or water in order to form syngas (containing $\mathrm{CO}_{2}, \mathrm{CO}, \mathrm{H}_{2}$ etc.). Research in coal gasification is done in order to understand kinetics and influences of particle size, gas flow, gas cleaning etc. in the process. Some results of coal gasification studies done at the Technical University of Munich $^{1,2}$ by means of STA-HP at pressures up to 50 bar and temperatures up to $1100^{\circ} \mathrm{C}$ will be shown. The evolved gas analysis (EGA) was done by mass spectroscopy and FT-IR spectroscopy. The latter one was achieved by direct analysis of the evolved gases above the sample by optical ports in the STA-furnace in order to prevent changes of composition before analyses.

\section{References}

1. T. Hasselsteiner et al., 8th European Conference on Coal research and its applications, 6-8 September 2010; Leeds, Great Britain
2. A. Tremel et al., 10th European Gasification Conference, 4-6 October 2010, Amsterdam, The Netherlands 